\title{
Recent Trend of Power Feeding Technique for Electric Railways
}

\author{
Yoshifumi MOCHINAGA \\ General Manager, \\ Power Supply Technology Div.
}

\begin{abstract}
To supply high-quality power to electric cars, it is required to technically study power conversion at substations, power supply to feeding circuits, current collection using contact lines and pantographs, measurement and maintenance. The power supply technology development division consists of three groups called the power supply systems group, the current collection maintenance group and the contact line structure group.

Recently, the advancement of microelectronics and power electronics led to the remarkable development of control, measurement and power converter in the field of electric railway.
\end{abstract}

This paper describes several results of the development.

Keywords : power feeding system, protective system, suppression of voltage fluctuation, overhead contact system, measuring apparatus for contact wires

\section{Introduction}

In the power feeding technology of railway, it is required to supply high-quality power to electric cars. Recently, power electronics has developed remarkably. The advancement of power electronics led to the introduction of VVVF controlled cars to replace the conventional cars driven by d.c. motors. Therefore, a power feeding system suitable for the VVVF controlled cars must be developed.

The technique of measurement and maintenance has also advanced in the same way as the control and power conversion technique. On the other hand, contact wires are stretched with high tension and new materials with high wear resistance have been developed for high-speed operation.

These new technical fields of power feeding system are outlined in this paper.

\section{Present power feeding system}

The first electric railway owned by the Japanese National Railways (JNR) started operation in 1906 on the Chuo Line that had been electrified at 600V d.c. in 1904 between Ochanomizu and Nakano in Tokyo, which belonged to Kobu Railways before purchased by JNR. The $600 \mathrm{~V}$ d.c. system was later replaced by a $1200 \mathrm{~V}$ d.c. system, and again by a $1500 \mathrm{~V}$ d.c. system. The $1500 \mathrm{~V}$ d.c. system is still used by all d.c. electric railways in Japan.

To cope with the increases in traffic, a study began on railway electrification based on the commercial frequency single-phase alternating current.

The success of fundamental test results led to the first commercial operation followed by a $20 \mathrm{kV}$ single-phase alternating current system with boosting transformers (BT) in 1957 on the Senzan and Hokuriku Lines. In 1964, Tokaido Shinkansen started operation by using a BT power feeding system, and marked unprecedented highspeed train operation at a maximum speed of $210 \mathrm{~km} / \mathrm{h}$.

Furthermore, an AT power feeding system was de- veloped for high-speed operation to supply power for long power feeding distances, as the standard system for a.c. electric railways in Japan. A coaxial cable power feeding system was also developed as a power feeding system for sections of limited space such as those in the Tokyo metropolitan area.

Table 1 shows the electric railway systems in Japan.

As of 1997, the commercial operation by JR covers a length of $18,094.5 \mathrm{~km}$. In the narrow-gauge railways, the rate of electrification is $54.7 \%$ with a length of $6215.0 \mathrm{~km}$ electrified at $1500 \mathrm{~V}$ d.c. and $3,682.3 \mathrm{~km}$ at $20 \mathrm{kV}$ a.c. Of the a.c. power systems, the BT type accounts for $57 \%$ and the AT type for $43 \%$.

Shinkansen is now operated for a length of $2036.5 \mathrm{~km}$. Shinkansen uses an AT $25 \mathrm{kV}$ power feeding system except for in the Tokyo metropolitan area where a coaxial cable power feeding system is used.

Table 1 Electric railway systems

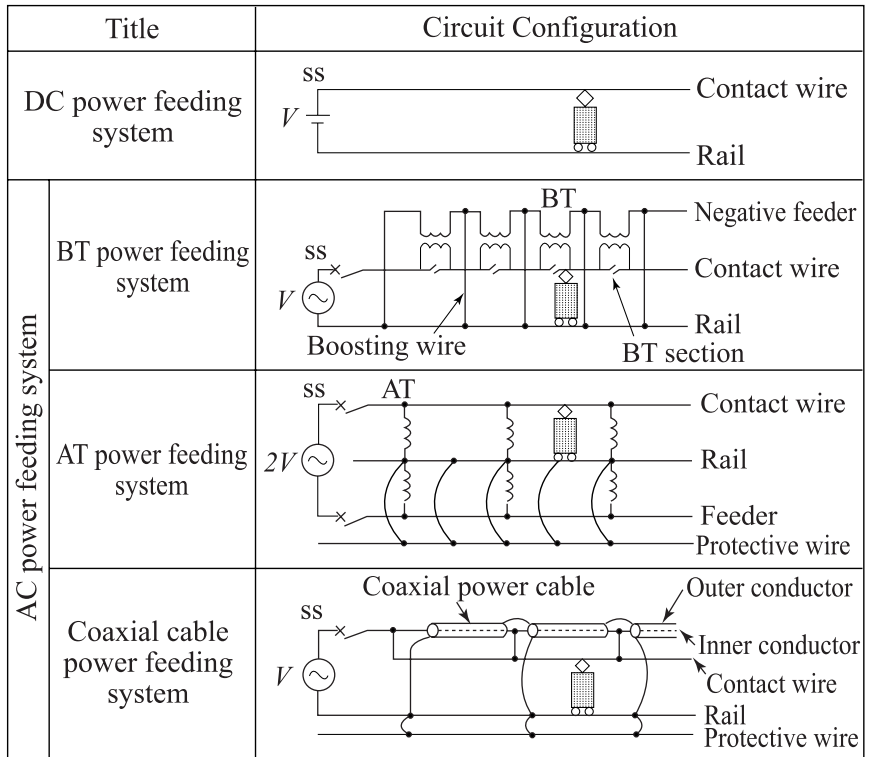




\section{Technical trend of d.c. power feeding circuit}

As a system for driving electric cars, VVVF control, which is able to drive three-phase induction motors by inverter, is now in use. Therefore, a power feeding system suitable for VVVF controlled cars will have to be developed.

\subsection{Device for transformation}

A silicon rectifier has been used since the 1960 s as a device to convert three-phase alternating current to direct current.

A 6-pulse rectifier was used for the three-phase rectifier. However, a 12-pulse rectifier shown in Fig. 1 has recently been introduced because of less distortion in the voltage waveform on the three-phase a.c. side.

A thyristor rectifier that is able to control the output voltage has been adopted in some cases to efficiently use regenerative power.

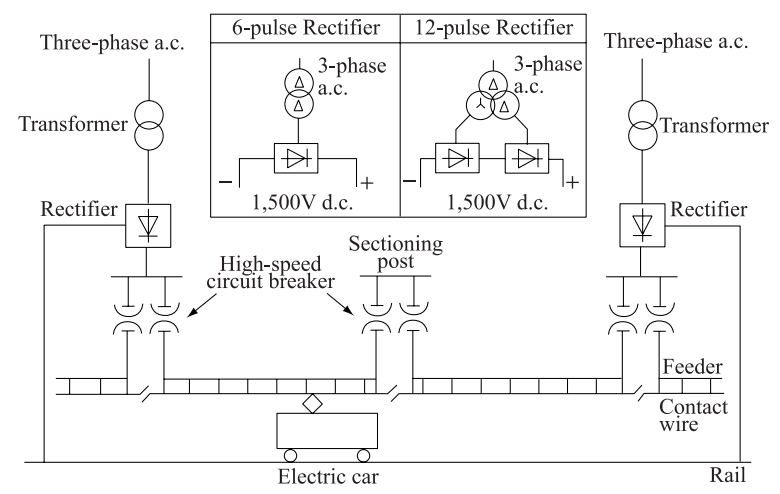

Fig. 1 Structure of d.c. feeding system

\subsection{Protective system}

A delta-I type fault selective relay has been used to detect faults in the d.c. power feeding circuit. The deltaI type fault selective relay detects changes in the fault current.

On the other hand, a window type fault selective relay has recently been developed not to detect the changes in the reverse current by the regenerative braking current.

As a large current flows when a fault occurs in the d.c. power feeding circuit, an air circuit breaker that has a mechanical structure is widely used at d.c. substations.

A GTO circuit breaker and a vacuum circuit breaker have been developed and are used in some private railway companies. It is very quiet in operation and does not need maintenance.

In order to break a d.c. current, the GTO circuit breaker has a non-liner resistance, while the vacuum circuit breaker has a non-liner resistance and a commutation circuit to pass a current in reverse to the main current.

Fig.2 shows the main circuit composition of vacuum circuit breaker.

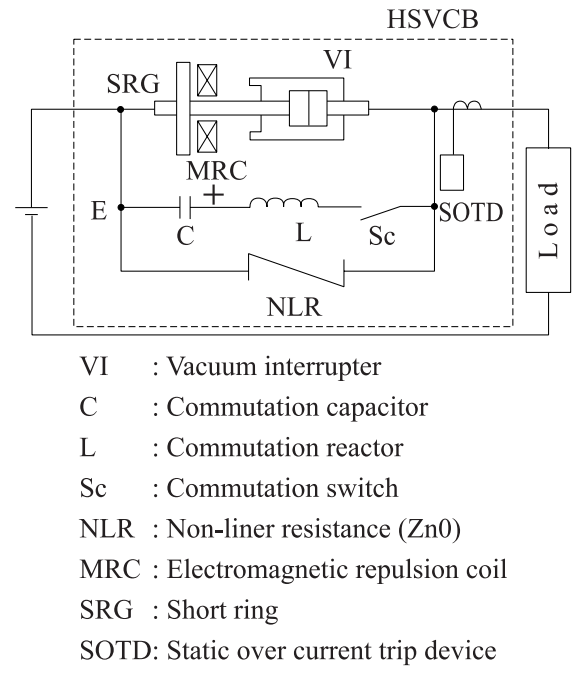

Fig. 2 Composition of vacuum circuit breaker

\section{Technical trend of a.c. power feeding circuit}

\subsection{Suppression of voltage fluctuation}

In an a.c. power feeding system, a feeding transformer converts three-phase power into a pair of single-phase power. Furthermore, the electrical capacity has been increased for high-speed operation. Therefore, voltage fluctuation may occur in the power received from the utility power line. On the other hand, the remarkable advancement of power electronics has brought the possibility of large power control.

Two examples are given below to explain the practical applications of power electronics. One is a static var compensator (SVC) that compensates for the reactive power by way of thyristor. The other is a single-phase feeding power conditioner(SFC) that is able to balance three-phase currents by using self-commutated inverters.

Fig. 3 shows the composition of SFC that is put into practical use at the substation of Nagano Shinkansen car depot.

As shown in Fig.3, self-commutated inverters are connected on the power feeding side to convert three-phase power into single-phase power.

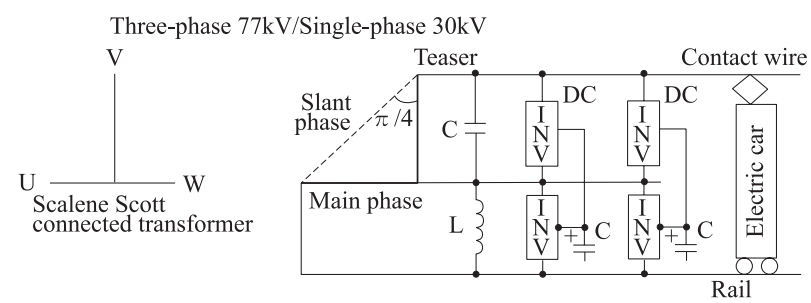

Fig. 3 Composition of single-phase feeding power conditioner(SFC)

\subsection{Protective system}

PWM-controlled cars with high efficiency and low harmonics that drive induction motors by inverter have 
increased in place of the conventional thyristor controlled cars. Therefore, the protective systems for power feeding systems are changing.

(1) Protection of power feeding circuit

Combined protective relays composed of a distance relay and an a.c. delta-I type fault selective relay are used to protect the power feeding circuit. Fig. 4 shows the protective area of the combined protective relays.

Recently, a digital relay has been used as a protective relay. The digital relay can distinguish the load current from a fault current by detecting a harmonics current, voltage drop and the current phase.

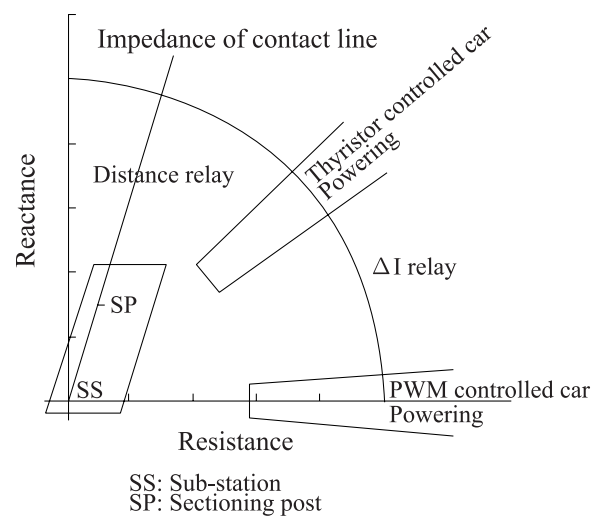

Fig. 4 Protective zone of a.c. electric railway protective relay

(2) Relay for detecting fault of changeover switchgear

At a substation or sectioning post of Shinkansen power feeding system, a pair of single power with different phases are jointed, and a particular section which is called a changeover section is installed to switch power supply by a changeover switchgear in accordance with the position of electric car.

As a fault detecting method of a changeover switchgear, a new system has been developed as shown in Fig.5. The system can detect the fault of changeover switchgear when a current simultaneously flows in a pair of changeover switchgears. To detect the current, optical current transformers are used, which can easily be installed at limited spaces.

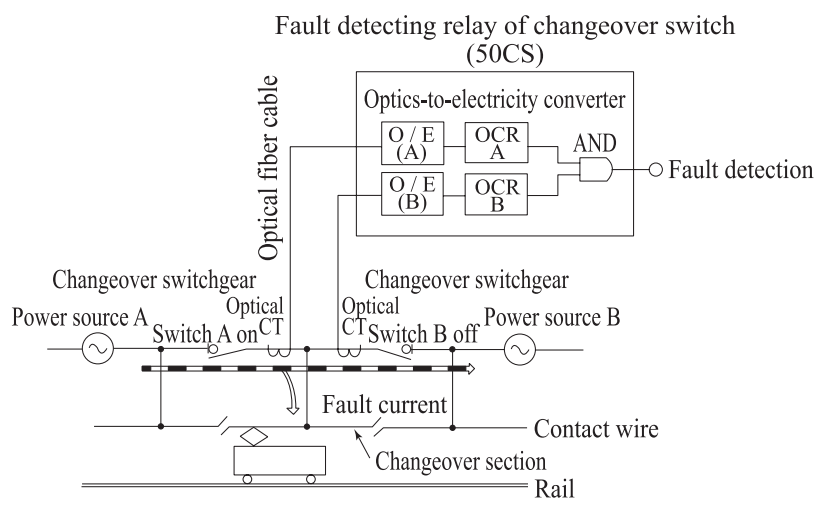

Fig. 5 Composition of fault detecting relay of changeover switch using optical current transformer

\section{Technological trend of current collection}

\subsection{Development for speedup}

Technical development of the overhead contact system is required to achieve an operation of $270 \mathrm{~km} / \mathrm{h}$ or $300 \mathrm{~km} / \mathrm{h}$ at Shinkansen.

For high speed operation, the tension of contact wire is strengthened so that the wave propagation velocity is raised.

For this purpose, a CS contact wire or a TA contact wire have been developed.

As shown in Fig.6, a CS contact wire has steel wires inside that is covered by copper. TA contact wire has a rectangular steel wire inside that is covered by aluminum.

When the recycling of contact wire is taken into consideration, however, it is advantageous to make contact wires from the same material. A new contact wire precipitation hardened copper alloy (PHC), which is made of $\mathrm{Cu}, \mathrm{Cr}$, and $\mathrm{Zr}$, has been developed and is actually used.

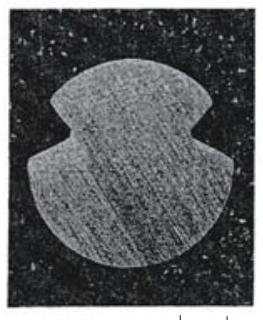

$3 \mathrm{~mm}$

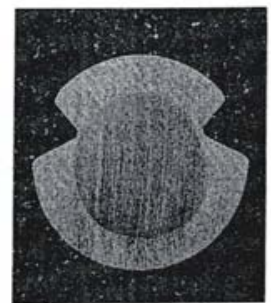

$3 \mathrm{~mm}$

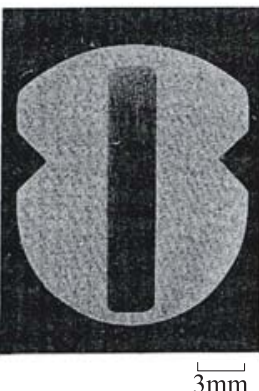

(c) Aluminium-clad steel (a) Hard-drawn copper (b) Copper-clad steel

Fig. 6 Cross section of contact wire

\subsection{Measurement technology}

In order to supply stable electric power, it is important to maintain overhead contact wire lines in a good state. For this reason, various measuring instruments are put to practical use.

(1) High-precision optical contact loss measuring instrument

The contact loss rate is an index to judge the quality of the contact state between contact wire and pantograph. The method of measuring the light of the arc generated when the wire and pantograph separate is one of the methods of measuring this contact loss rate. We developed a measuring instrument that can measure this arc light at high accuracy. This measuring instrument is constituted by an optical fiber with a length of $20 \mathrm{~m}$ and a light detection device. We install the tip of the optical fiber on the roof of a car, and install the detection device in the car. Arc light transmits through the optical fiber and goes into the detection device.

(2) Measuring apparatus for contact wire wear using sodium vapor lamps 


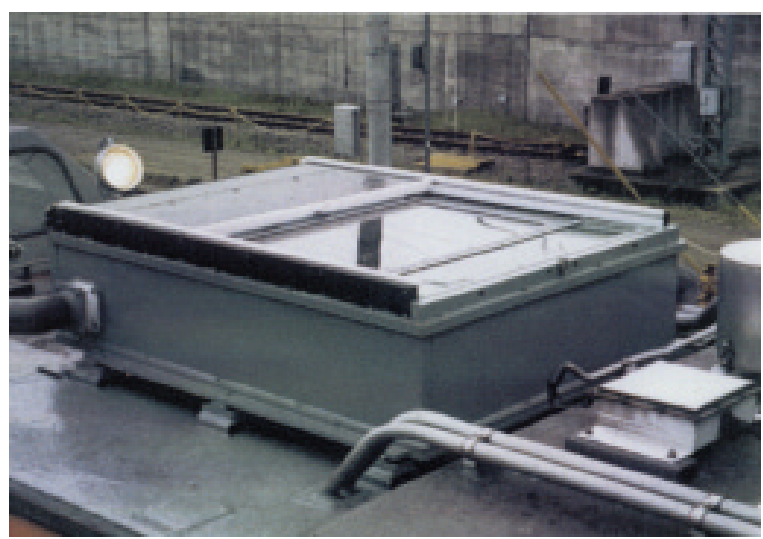

Fig. 7 Measuring apparatus for contact wire wear

This measuring apparatus for contact wire wear measures the width of wear surface by a CCD line sensor camera shown in Fig.7, which illuminates the contact wire by sodium vapor lamps. It can measure at commercial speed even in daytime.

(3) The device for detecting deterioration of electric wires

Hard-drawn aluminum stranded wires, hard-drawn copper stranded wires, aluminum conductor steel reinforced, etc. are used for the feeder of overhead contact lines. The device, which diagnoses the deterioration of these electric wires, is shown in Fig. 8. This device using the change of eddy current is put to practical use.

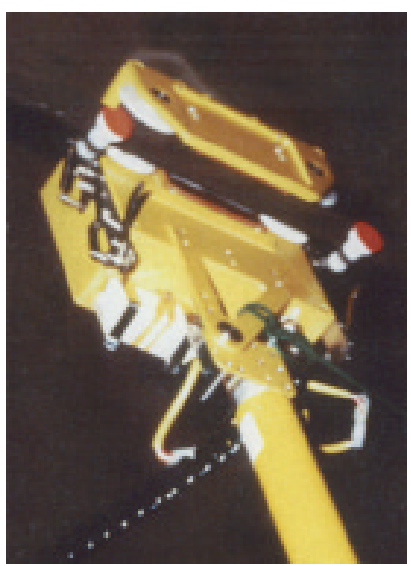

(a) Detector

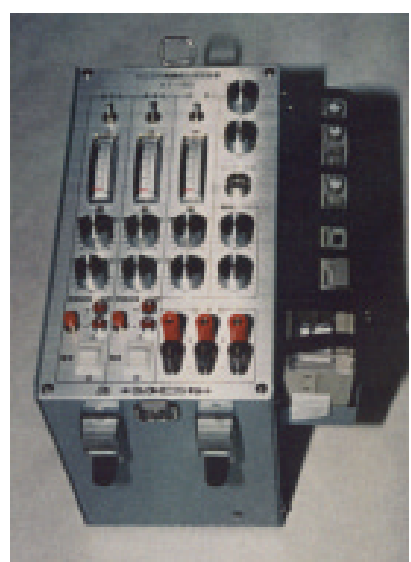

(b) Data-processor unit
Fig. 8 The device for detecting deterioration of aluminum conductor steel reinforced

\section{Conclusions}

A power feeding system is an important and fundamental technology for stable operation of electric cars. The advancement of electronics changed the technology of electric railways. As a result, electric cars are now able to run at high-speed. The technical development for the global environment, energy and maintenance will be advanced further. 